\title{
As interfaces do desenvolvimento local em 21 edições da revista Interações (2000-2010)
}

\author{
The interfaces of local development in 21 editions of Interações journal \\ (2000-2010)
}

Las interfaces del desarrollo local en 21 ediciones de la revista Interações

(2000-2010)

\author{
Karen Giuliano ${ }^{1}$ \\ Luciane Almeida ${ }^{1}$ \\ Maria Augusta Castilho ${ }^{1}$
}

Recebido em 05/05/2020; revisado e aprovado em 10/08/2020; aceito em 21/08/2020

DOI: http://dx.doi.org/10.20435/inter.v21i4.3042

\begin{abstract}
Resumo: A presente pesquisa estudou a revista Interações sob a ótica dos conceitos e das práticas de desenvolvimento local. Objetivou destacar e identificar os conceitos e as práticas de desenvolvimento local inseridos em 21 edições da revista Interações, da Universidade Católica Dom Bosco (UCDB), nos períodos de 2000 a 2010. O trabalho, além do seu valor histórico, é classificado pelo método indutivo com abordagem qualiquantitativa para compreender os fenômenos de desenvolvimento local. Além do mais, tem especificidade exploratória e analítica, fazendo-se uso da pesquisa bibliográfica descritiva para oferecer ao leitor as concepções teóricas acerca dos conceitos de desenvolvimento local, com observações e experiências de trabalhos empíricos. Estabeleceu-se como objetivo das questões norteadoras deste estudo: apresentar a importância da revista Interações para docentes e discentes do Programa de Mestrado em Desenvolvimento Local, como também explorar e destacar seus marcos teórico-conceituais e o levantamento dos dados gerais dos artigos publicados (2000-2010). Os resultados identificaram 22 artigos científicos publicados na revista Interações (2000-2010) que tratam de cultura, identidade e diversidade na dinâmica territorial, com a inclusão de relatos e entrevistas sustentados por meio de pesquisas acerca dos conceitos e das observações práticas da temática. Concluiu-se que os resultados da pesquisa podem contribuir com a difusão de conhecimento entre docentes, discentes, pesquisadores, agentes locais e demais interessados no assunto em âmbito nacional e internacional.
\end{abstract}

Palavras-chave: artigos científicos; desenvolvimento local; revista Interações.

Abstract: This research studied the Interações journal from the perspective of concepts and practices of local development. It aimed to highlight and identify the concepts and practices of local development inserted in 21 editions of Interações journal from the Catholic University Dom Bosco (UCDB), in the periods from 2000 to 2010. The work, in addition to its historical value, is classified by the inductive method with a qualitative and quantitative approach to understanding the phenomenon of local development. In addition, it has exploratory and analytical specificity, making use of descriptive bibliographic research to offer the reader theoretical conceptions about the concepts of local development, with observations and experiences of empirical works. We established as objective of the guiding questions of this study: the importance of Interações journal for teachers and students of the Master's Program in Local Development, as well as exploring and highlighting its theoretical-conceptual frameworks and the survey of the general data of published articles (2000-2010). The results identified 22 scientific articles published in Interações journal (2000-2010) that deal with culture, identity, and diversity in the territorial dynamics, with the inclusion of reports and interviews sustained through research on the concepts and practical observations of the theme. We concluded that the results of the research can contribute to the dissemination of knowledge among teachers, students, researchers, local agents, and others interested in the subject at national and international levels.

Keywords: scientific articles; local development; Interações journal.

Resumen: La investigación estudió la revista Interações de la perspectiva de los conceptos y prácticas de desarrollo local. Su objetivo fue resaltar e identificar los conceptos y prácticas de desarrollo local insertados en 21 ediciones de la revista Interações, de la Universidad Católica Dom Bosco (UCDB), en los períodos de 2000 a 2010. El trabajo, además de su valor histórico, se clasifica por el método inductivo con enfoque cualitativo

\footnotetext{
${ }^{1}$ Universidade Católica Dom Bosco (UCDB), Campo Grande, Mato Grosso do Sul, Brasil.
} 
y cuantitativo para comprender los fenómenos del desarrollo local. Además, tiene especificidad exploratoria y analítica, haciendo uso de la investigación bibliográfica descriptiva para ofrecer al lector concepciones teóricas sobre los conceptos de desarrollo local, con observaciones y experiencias de trabajos empíricos. Se estableció como objetivo de las preguntas orientadoras de este estudio: presentar la importancia de la revista Interações para maestros y estudiantes del Programa de Maestría en Desarrollo Local, así como explorar y resaltar sus marcos teórico-conceptuales y la encuesta de los datos generales de los artículos publicados (2000-2010). Los resultados identificaron 22 artículos científicos publicados en la revista Interações (20002010) que abordaran la cultura, la identidad y la diversidad en la dinámica territorial, con la inclusión de informes y entrevistas sostenidos a través de la investigación sobre los conceptos y observaciones prácticas del tema. Se concluyó que los resultados de la investigación pueden contribuir a la difusión del conocimiento entre maestros, estudiantes, investigadores, agentes locales y otros interesados en el tema a nivel nacional e internacional.

Palabras claves: artículos científicos; desarrollo local; revista Interações.

\section{INTRODUÇÃO}

O desenvolvimento local tem despertado crescente interesse e envolvimento de estudiosos pesquisadores, análise observada pelas pesquisas realizadas pelo Programa de Mestrado/ Doutorado em Desenvolvimento Local, da Universidade Católica Dom Bosco (UCDB), lugar em que docentes e discentes colaboram e se dedicam para o progresso dos espaços e territórios.

A Interações é a revista internacional de desenvolvimento local do Programa de Pós-Graduação em Desenvolvimento Local da Universidade Católica Dom Bosco. É composta por pesquisas cujas temáticas se relacionam à "Cultura, Identidade e Diversidade na Dinâmica Territorial", bem como às "Políticas Públicas e Dinâmicas de Inovação em Desenvolvimento Territorial".

Assim, a metodologia da pesquisa é quantitativa e qualitativa, com objetivos descritivos e analíticos, executados por meio de pesquisas bibliográficas, sendo que, de início, antes mesmo da definição plena do tema, foram levantados diversos artigos, dissertações e livros que evidenciavam conceitos e práticas de desenvolvimento local e seus resultados, ou seja, se exitosos ou infrutíferos, para se conhecer o material de cunho exploratório com a finalidade de se realizar análise e alcançar resultados.

Com a evidência de consideráveis fontes de pesquisa sobre desenvolvimento local, as questões norteadoras deste trabalho tiveram como objetivo apresentar a importância da revista Interações para os discentes do Programa de Mestrado em Desenvolvimento Local, bem como para a sociedade, que tem interesse na aquisição de conhecimentos acerca da temática; explorar e destacar os marcos teórico-conceituais, na sua originalidade, discorridos pelos autores que publicaram nas 21 edições da revista Interações (2000-2010); despertar a continuidade das pesquisas e viabilizar a revelação de tantos outros resultados de pesquisas que possam expor as dificuldades e os desafios locais que precisam ser refletidos e trabalhados.

\section{O DESENVOLVIMENTO LOCAL SOB ANÁLISE DOS PESQUISADORES LOCAIS}

A inserção do desenvolvimento local no programa de mestrado e doutorado da Universidade Católica Dom Bosco se deu de forma gradativa, com o esforço concentrado de professores e pesquisadores das diversas áreas do conhecimento.

Nesse sentido, Ávila (2000), no relato intitulado “Pressupostos para formação educacional em desenvolvimento local", percebe que a utilização da expressão desenvolvimento local é recente, sendo que em quaisquer regiões do mundo nem mesmo se falava em desenvolvimento 
local na década de 1970, o máximo que se mencionava era o desenvolvimento regional, próximo do final do ano de 1970, e, mais adiante, no período da década de 1980, por meio dos organismos internacionais como ONU, Unesco, BID, Bird, Usaid, FMI, entre outros, que pensavam e se posicionavam com estratégias governamentais de desenvolvimento.

Nesse sentido, o mesmo autor acima nominado enfatiza que o desenvolvimento local no ambiente universitário da Universidade Católica Dom Bosco começou a ser pensado e estruturado no ano de 1996, com o convite do professor geógrafo José Carpio Martín, para que um professor da Universidade Católica Dom Bosco fosse participar de um curso promovido pela Universidade de São Paulo com a temática de desenvolvimento local (ÁVILA, 2000).

Pode-se dizer que trocas de conhecimentos sobre desenvolvimento local despertaram um novo cenário na academia do Programa de Mestrado em Desenvolvimento Local da Universidade Católica Dom Bosco, sendo que pesquisadores, de forma pioneira, em Campo Grande, MS, fomentaram as pesquisas relacionadas à temática.

A importância dedicada aos estudos de desenvolvimento local foi ratificada com o apoio da Universidade Complutense de Madri, que assinou convênio de parceria com a Universidade Católica Dom Bosco, para a formação de mestres e doutores em Desenvolvimento Local (ÁVILA, 2000, p. 67).

No mesmo artigo acima citado, o autor ainda se expressou surpreso, uma vez que a pesquisa do novo processo de formação de desenvolvimento se manifestou inicialmente pela área da geografia, e não pelas ciências econômicas, sociais e políticas, como se presumia.

Coincidentemente, Ávila relata que, de forma similar, a Geografia foi a precursora do desenvolvimento local na Universidade de São Paulo, como também na Universidade Complutense de Madri - Espanha (ÁVILA, 2000, p. 67).

Persistente, este mesmo autor narra acerca da sua busca e observação de como estava sendo abordado o desenvolvimento local na academia da Universidade Católica Dom Bosco; ele registrou que, por mais de dois anos, presenciou debates envolvendo a árdua missão de conceituar o desenvolvimento local. Entre tantas ponderações, destacou alguns aspectos relevantes para o avanço da trajetória de investigação que aos poucos se iniciava (ÁVILA, 2000, p. 69).

$\mathrm{Na}$ análise acerca da conceituação de desenvolvimento local sob o ponto de vista de diversos autores, Ávila passa a observar que o desenvolvimento local era remetido apenas à melhoria de vida de uma determinada comunidade, com o requisito ímpar de que essa participasse do processo. Nesse aspecto, quando se refere à comunidade, o mesmo autor faz referência de que realizou desenvolvimento comunitário de 1968 a 1971 e menciona que, outrora, aquilo que se observava como desenvolvimento comunitário, hoje, pode-se compreender como desenvolvimento local.

Assim, percebe-se que o desenvolvimento local é possível quando se é observado, inicialmente, pelo agente inserido na comunidade, que a considera como parcela de si e se sente parte dela no todo (ÁVILA, 2000, p. 68).

Com efeito, sucessivos estudos da temática ganharam visibilidade e, por conseguinte, letrados professores e mestrandos iniciaram a execução das atividades práticas a partir dos estudos teóricos de desenvolvimento local, de modo que partilharam propostas e ações, ao passo que reuniram e publicaram os resultados da práxis na Interações - Revista Internacional de Desenvolvimento Local.

Inaugurando a primeira edição da revista Interações, Cleonice Alexandre Le Bourlegat, então coordenadora do Programa de Desenvolvimento Local, da Universidade Católica Dom Bosco, abordou no artigo intitulado "Ordem local como força interna de desenvolvimento" a importância da ordem interna de um local para que o desenvolvimento possa se concretizar, o que 
possibilitou identificar tal característica de ordem intrínseca como norteadora para a obtenção de resultados satisfatórios para o progresso de um local (BOURLEGAT, 2000, p. 20).

Na mesma abordagem, verificou-se que o desenvolvimento local propicia oportunidades para que a ordem seja estabelecida de dentro para fora, ou seja, a comunidade se organiza e se estrutura, e o Estado simplesmente ampara. Dessa forma, o artigo "A recomposição dos espaços" reafirma posições enfáticas no sentido de que: "O desenvolvimento local substitui, doravante, o desenvolvimento comandado por cima, estatizado e centralizador, que caracterizou, na França pós-Guerra, os 'trinta anos gloriosos'” (BENKO, 2001, p. 9).

Portanto o desenvolvimento local segue a abordagem de solidariedade com a finalidade de agregar forças internas e atenuar fraquezas, pensamento este presente no artigo "A rádio UCDB e o desenvolvimento local", de que "O Desenvolvimento Local é parte de uma visão de nova sociedade, constituída de baixo para cima, mediante a institucionalização e extensão paulatina de formas mais solidárias, preenchendo as lacunas, objetivando o crescimento: econômico, sócio e cultural, para reduzir as aflições, privações, disparidades e diferenças" (CASTILHO; DERMIRDJIAN, 2004, p. 61).

Em tal perspectiva, Ávila, em 2006, no artigo "Realimentando discussão sobre teoria de desenvolvimento local", conduz o estudo de desenvolvimento local valendo-se do entendimento de que este deve ser observado, primeiramente, a partir de um universo de informações, para que dessas se filtrem as singularidades, para se extrair de um estudo macro as necessidades e oportunidades de âmbito local, no sentido de que se pense posteriormente na execução de microestratégias locais.

Com esteio nas ideias de Maciel (2008), no artigo intitulado "Exame de ressonância sobre paciência e desenvolvimento local endógeno em subsolo teológico", colabora com a necessidade de reflexão de se ter paciência para que o processo de desenvolvimento local aconteça, uma vez que o ser impaciente "[...] aborta processos históricos e perde a oportunidade, exatamente porque aqui trata-se de encontrar a sintonia entre dois tempos: o tempo do homem individual, do que critica e avalia a situação [...]" (MACIEL, 2008, p. 100).

Na mesma constância e coerência de pensamentos e estudos, Silva, Lopes e Michon Junior (2009), no artigo nomeado "Intervenção do Estado e desenvolvimento local: uma análise cross section dos municípios paranaenses", aduzem ser a educação de suma importância quando nos referimos ao processo de desenvolvimento local, uma vez que: "As teorias mais recentes sobre desenvolvimento, sempre apontam a importância da educação para o processo de desenvolvimento no longo prazo" (SILVA; LOPES; MICHON JUNIOR, 2009, p. 48).

Acompanhando as ideias propostas, lorio et al. (2009), no artigo designado "A perspectiva da educação ambiental e o processo histórico do saneamento básico: a instalação das redes de água e esgoto nos municípios de Campo Grande/MS e Dourados/MS", também defendem que o desenvolvimento responsável acontece quando a educação é introduzida de forma preventiva na sociedade, sendo que, por meio dela, as mudanças comportamentais podem acontecer e o grupo local passa a ter a possibilidade de refletir sobre suas condutas, compreendê-las, aprender, desenvolver e preservar o meio em que vive (IORIO et al. 2009, p. 64).

Mais adiante, a cronologia a respeito do desenvolvimento das pesquisas segue com Castilho, Arenhardt e Bourlegat (2009), com o artigo "Cultura e identidade: os desafios para o desenvolvimento local no assentamento Aroeira, Chapadão do Sul, MS", sustentando que o desenvolvimento local tem como sujeito principal o homem, que tem a capacidade de executar o processo de mudança do local e proporcionar satisfação para a comunidade como um todo, 
assim, "[...] o desenvolvimento local é: entendido como um processo de transformação, que envolve o ser humano como o principal beneficiário dessa mudança, numa perspectiva de melhoria da qualidade de vida de uma coletividade ou grupo de pessoas que fazem parte de uma comunidade" (CASTILHO; ARENHARDT; BOURLEGAT, 2009, p. 160).

Logo, frisa-se similarmente que as pessoas que vivem em uma determinada localidade, em comunhão, sejam as principais interessadas no desenvolvimento da comunidade, e que estas se façam agentes motivadoras e executoras das realidades que almejam e esperam. Nesse sentido, as autoras reforçam que os seres humanos envolvidos nas ações de interesses relacionados ao desenvolvimento da coletividade se sentem orgulhosos e partes integrantes do processo de busca pelas predileções comuns de melhoria, e "O desenvolvimento local parte da perspectiva da valorização humana como sujeito de seu próprio desenvolvimento. A práxis do desenvolvimento pode ser entendida como o exercício para uma ação mais efetiva que envolve o indivíduo [...]" (CASTILHO; ARENHARDT; BOURLEGAT, 2009, p. 160).

Observa-se, portanto, nas análises dos pesquisadores, a importância dos agentes locais na percepção da realidade em que se encontram, da sua interação com o local e com a comunidade, como também da consciência acerca do desabrochar do sentimento de pertença àquele espaço em que se vive (CASTILHO; ARENHARDT; BOURLEGAT, 2009, p. 161).

Nesse contexto, o sentimento de pertença ganha foco com Costa et al. (2010), no artigo "Democracia e desenvolvimento local em assentamentos rurais", e conquista relevância ímpar quando os agentes locais passam a se reconhecer como parte integrante do meio em que fazem morada, como também, quando conseguem desfrutar da sensação de serem agentes de transformação, melhoria e de sustentação da realidade da comunidade.

Contudo, para que o desenvolvimento local aconteça, em conformidade com as ideias de Perry e Coelho (2010), no artigo "Argumentações acerca de questões técnico-científicas: disputas, valores e ideais de mundo", os pesquisadores têm a possibilidade de realizar a mediação "[...] entre as necessidades sociais do grupo e as soluções apresentadas pelo mundo da ciência, sob a forma de novas técnicas ou tecnologias" (PERRY; COELHO, 2010, p. 133), especialmente na atuação por meio de estudos e estratégias de desenvolvimento local nos espaços em que se acham conflitos de interesses locais. Impera, portanto, assinalar a importância de se ter sintonia nas ações das comunidades que aspiram por desenvolvimento local, uma vez ser a união dos agentes o fator potencializador para a condução dos processos interativos e estratégicos de desenvolvimento.

\section{ASPECTOS DA DINÂMICA TERRITORIAL LOCAL OBTIDOS POR MEIO DO DESENVOLVIMENTO LOCAL ENDÓGENO E DOS FATORES EXÓGENOS}

Para se entender a dinâmica territorial, torna-se essencial identificar os conceitos do desenvolvimento endógeno e fatores exógenos, bem como entender a dinâmica local, os pontos fortes e fracos.

\subsection{Desenvolvimento endógeno}

Com relação ao desenvolvimento endógeno, os artigos apresentados sob este tema abordaram conceitos, observações e resultados das ações locais, sendo destacado por Pires (2007), no artigo intitulado "As lógicas territoriais do desenvolvimento: diversidades e regulação", que o desenvolvimento por baixo, definido como desenvolvimento local endógeno, teve início 
em 1980, como afronta ao capitalismo que, desenfreado, se expressava e apoderava-se do poder, por meio de fortes movimentos de indústrias e empresas de grande porte; enquanto, do outro lado, a condição do meio ambiente e do capital humano se deteriorava.

Com a preocupação relacionada à situação das comunidades locais e do meio ambiente, os sujeitos locais iniciaram a intervenção pela busca de seus interesses; nesse sentido, utilizaramse de forças contrárias às forças advindas do capitalismo, com a execução de atividades de preservação e gestão das áreas povoadas. Tudo isso fomentou energias locais para aflorar a solidariedade e o autodesenvolvimento do espaço.

No entanto Ávila (2000) já estabelecia no relato "Pressupostos para a formação educacional em desenvolvimento local" que o desenvolvimento endógeno tem uma composição de "[...] potenciais, dinamismos e forças tanto individuais, familiares e coletivos quanto físicoambientais presentes explícita ou implicitamente no cotidiano de cada comunidade localizada [...]" (ÁVILA, 2000, p. 70). Contudo evidencia-se que a endogeneidade tem como característica forças entrelaçadas de agentes de desenvolvimento local, que juntas, na mesma realidade, proporção, sintonia, simetria, com a mesma visão e os mesmos interesses, conseguem se constituir estrategicamente e impulsionar com criatividade os agentes locais, para transformar uma realidade em outra realidade, resultando em saldos positivos os avanços da comunidade de um local (ÁVILA, 2000, p. 70).

Porém é preciso sensibilidade para perceber que o estado de inconsciência, desmotivação ou complexo de impotência da comunidade pode interromper o progresso local. Ávila (2000) menciona ainda, em sua pesquisa, a dificuldade da prática do desenvolvimento local endógeno em terra roxa, quando, dos poucos habitantes que ali faziam morada, não se achava união de forças para clamar por suas necessidades e desenvolvimento local, sendo que as pluralidades de forças negativas, positivas e interesses dissemelhantes davam origem à resistência na unidade e de conciliação dos agentes locais. Dessa forma, o autor percebeu que, como a comunidade não se reunia com a finalidade de buscar por melhores condições, o caminho era colocar em pauta as necessidades da comunidade em público, nesse caso, em eventos religiosos.

No mesmo sentido, para ilustrar a relevância do desenvolvimento endógeno, Coelho e Ávila (2009) publicaram a pesquisa intitulada "Performances comunitárias e vieses teóricos sobre potencialidades de participação no Jardim Sayonara - Campo Grande-MS - na ótica de desenvolvimento local", com as observações resultantes dos envolvimentos expressivos da comunidade local Jardim Sayonara, com a percepção de que cada agente local, com seus próprios conhecimentos, suas próprias especificidades, experiências de vida e vivências, contribuem para a formação e desenvolvimento da localidade, assim, a necessidade maior de contribuição e parceria está relacionada com a capacidade que cada sujeito possui para participar e contribuir. Portanto o desenvolvimento endógeno deve acontecer naturalmente com a inclusão de todos os agentes locais interessados, deixando-se de lado o processo de seleção dos indivíduos.

Com os resultados da pesquisa executada no Jardim Sayonara, ao apresentar a importância da compreensão e interação existentes entre as forças endógenas e exógenas, foi possível identificar o potencial presente na colaboração dos agentes locais.

Ainda nesse contexto, Coelho e Ávila (2009) evidenciaram a importância do desenvolvimento local participativo, trazendo resultados satisfatórios no trabalho desenvolvido no Jardim Sayonara, e relataram que os "[...] habitantes [do bairro] não só começaram a descobrir endogenamente que a união faz a força como também dela aprenderam a fazer uso para ações, reinvindicações 
e conquistas [...]" (COELHO; ÁVILA, 2009, p. 105). Destacaram, assim, o resultado do processo de participação endógena como força para o desenvolvimento da comunidade local. Os mesmos autores abordaram ainda, no dedicado estudo acerca da região, que a comunidade local passou a sentir orgulho de fazer parte do grupo que organizou e executou a construção do todo da comunidade do Jardim Sayonara para se chegar ao que ela representa atualmente, apresentandose o ânimo como uma constante de todos os depoentes.

Diferentemente do êxito da pesquisa realizada no Jardim Sayonara, infrutíferos se fizeram os resultados alcançados no projeto relacionado à pesquisa de Saraiva e Callou (2009), intitulada "Políticas públicas e estratégias de comunicação para o desenvolvimento local de comunidades pesqueiras de Pernambuco", em que participantes do projeto decidiram mobilizar a comunidade pesqueira por meio de iniciativas exógenas, utilizando-se de comunicações e marcando reuniões com os agentes locais com a tentativa de instruí-los e mobilizá-los à integração no Projeto Renascer (SARAIVA; CALLOU, 2009, p. 73 ). Ocorreu que as iniciativas exógenas não movimentaram a comunidade, e os resultados não foram efetivos, isso se deu pela ausência de potencialidades endógenas, de agentes locais preparados e entusiasmados para pleitear o desenvolvimento daquela região.

Observa-se, contudo, que o desenvolvimento local exige cautela profunda e minuciosa análise de todo o contexto de uma comunidade: suas necessidades, fragilidades, potencialidades e interesses dos agentes locais em executar e mudar uma ou várias realidades locais. 0 desenvolvimento endógeno facilita a obtenção de resultados satisfatórios para a comunidade, uma vez que são os próprios agentes locais que vivenciam suas realidades e reconhecem as principais necessidades do território.

Identifica-se, em outra pesquisa, o desenvolvimento endógeno, desta vez, nas comunidades tradicionais Kaiowá e Guarani, a partir do artigo "Recursos genéticos, biodiversidade, conhecimento tradicional Kaiowá e Guarani e o desenvolvimento local", de autoria de Rego, Brand e Costa (2010), que retrata o movimento dos agentes locais, com auxílio dos pesquisadores externos, na percepção da necessidade de readequar as questões ambientais e a qualidade de vida da comunidade; para tanto, uniram os conhecimentos tradicionais com o alicerce de pesquisadores com o propósito de obtenção de alternativas saudáveis.

Destaca Bourlegat (2000, p. 15), no artigo intitulado "Ordem local como força interna de desenvolvimento", que a fase entrópica, é "[...] caracterizada pelo esforço criativo dos intelectuais, no sentido de propor novas formas de organização da vida".

Para que os agentes locais consigam pôr em prática a execução de projetos capazes de transformar a realidade da comunidade, estratégias de desenvolvimento são de suma importância para o adequado planejamento, organização e execução das atividades, já que amparam e possibilitam a segurança e a solidificação das ações, propiciando maior probabilidade de eficácia dos resultados propostos nos objetivos (BOURLEGAT, 2000, p. 16).

A atuação do desenvolvimento endógeno com a intermediação de pesquisadores se faz singular. Pôde-se verificar isso quando Rego, Brand e Costa (2010, p. 58-59) destacaram a importância da parceria de pesquisadores inseridos no projeto Kaiowá/Guarani, executado pela Universidade Católica Dom Bosco, para atender a situação da comunidade e auxiliar nas necessidades locais.

Para que os resultados fossem positivos, pesquisadores utilizaram-se de entrevistas, reuniões com a equipe técnica, discussão de propostas com a comunidade, valendo-se principalmente dos conhecimentos dos índios mais velhos, denominados de "informantes raros" como forma de enriquecer a pesquisa e a readequação da nova realidade. 
Como já registrado por Bourlegat (2000, p. 15), "[...] as narrativas orais resgatam, valorizam e transmitem, de uma geração a outra, as experiências coletivas do passado" e, de acordo com a mesma autora, "[...] a codificação escrita da linguagem é, portanto, o resultado de nova criatividade do mundo mental diante das ameaças de natureza entrópica no processo de comunicação e ordenação da sociedade". Validar todos os tipos de ferramentas para a pesquisa permite um conhecimento mais profundo do objeto a ser estudado. Assim, o desenvolvimento endógeno é consagrado pela atuação de agentes locais na busca pela satisfação das necessidades da comunidade, tendo como vantagem relevante a disponibilidade e ação de letrados pesquisadores para dar suporte e nortear os objetivos e atividades idealizadas.

\subsection{Fatores exógenos}

O desenvolvimento pode acontecer em determinada localidade por fatores exógenos, também conhecidos e citados como desenvolvimento exógeno ou desenvolvimento por cima, assim, destacam-se na presente pesquisa ações que se manifestam por meio de sujeitos que não se encontram inseridos diretamente na comunidade, não sentem o ambiente e nem sequer vivem naquele espaço. Portanto as intervenções no local acontecem por escolhas alheias às vontades e consultas da comunidade.

Ávila posiciona no relato "Pressupostos para Formação Educacional em Desenvolvimento Local" que a expressão mais bem aplicada às condutas que acontecem de cima para baixo nas comunidades é denominada de fatores exógenos (ÁVILA, 2000, p. 70). Em tal perspectiva, Ávila ainda faz referência desse tipo de desenvolvimento como desenvolvimento no local, e não desenvolvimento local, sendo que, para acontecer o desenvolvimento local, considera-se o desenvolvimento endógeno, ou seja, "[...] a própria comunidade assume o agenciamento do seu desenvolvimento e os agentes externos são os que se envolvem participando [...]" (ÁVILA, 2000, p. 69). Já o desenvolvimento no local é aquele em que "[...] quaisquer agentes externos se dirigem à 'comunidade localizada' para promover as melhorias de suas condições e qualidade de vida, com a 'participação ativa' da mesma [...]" (ÁVILA, 2000, p. 69). O artigo intitulado "Intervenção do Estado e desenvolvimento local: uma análise cross section dos municípios paranaenses", de Silva, Lopes e Michon Junior (2009), faz uma análise da efetividade das ações exógenas e pontua que esse tipo de intervenção pode afetar de forma positiva as ações locais programadas para curto ou longo prazo, devendo ocorrer para atenuar as desigualdades entre os municípios do Sul do país, como o Paraná. Porém o mesmo autor, mais adiante, na mesma pesquisa, verificou a ineficiência das ações exógenas com a finalidade de reduzir as desigualdades sociais do local, sendo que "[...] as finanças públicas ainda não representam um papel efetivo para mudança das desigualdades socioeconômicas dos municípios paranaenses" (SILVA; LOPES; MICHON JUNIOR, 2009, p. 51). Com isso, constata-se que o fator exógeno não é aquele manifestado por meio da utilização do capital humano do local, da junção de forças locais para satisfação das necessidades, da interação, integração e ações impulsionadoras dos agentes locais, este seria o conceito de desenvolvimento endógeno; exógeno, portanto, são aquelas forças em que os agentes locais observam os acontecimentos sem ou com poucas possibilidades de intervenção.

Nesse sentido, em 2010, Grzeszczeszyn e Machado publicaram o artigo "Políticas públicas para o desenvolvimento local: o caso de fomento às indústrias de móveis de Guarapuava, Paraná", em que pesquisaram as políticas públicas para a estimulação da produção de móveis em série e o 
trabalho conjunto entre empresários do setor. Esses mesmos autores abordaram, de início, alguns papéis importantes das políticas públicas e destacaram que "[...] o setor público assume um papel fundamental como estimulador das inovações [...]" (GRZESZCZESZYN; MACHADO, 2010, p. 82), auxiliando no processo de autodesenvolvimento, "[...] provendo recursos necessários para a execução dos projetos oriundos das iniciativas das comunidades" (p. 83). Entretanto, do que consta no resultado da pesquisa, as ações exógenas não foram frutíferas pelas iniciativas exógenas, lideranças públicas, desarticulação política junto à comunidade, entre outros (GRZESZCZESZYN; MACHADO, 2010, p. 86).

Pode-se observar, portanto, que o fator exógeno necessita do movimento endógeno para que seja eficaz, esclarecendo-se, assim, que as lideranças da sociedade, o poder público e os projetos exógenos não são capazes de promover resultados positivos se os agentes locais não forem incluídos nas propostas, como também se as necessidades locais estiverem desalinhadas dos programas e desatentos às realidades locais.

Outra pesquisa que também produziu resultados acerca da aplicabilidade da endogeneidade e dos fatores exógenos locais intitulou-se "Políticas públicas e extensão pesqueira em Cabedelo, Paraíba", que teve a finalidade de analisar o desenvolvimento das políticas públicas aplicadas no segmento pesqueiro. Os resultados demonstrados nos projetos em execução não lograram êxito pelos seguintes motivos: no Centro de formação em Pesca e Cultura Marinha, houve "[...] uma baixa demanda desses cursos pelos pescadores e pescadoras, apesar do entusiasmo observado entre os que participaram dessa formação" (MENDES FILHO; CALLOU; SANTOS, 2010, p. 96). No Programa Pescando Letras, constatou-se que "[...] os cursos de alfabetização de jovens e adultos para pescadores deveriam ser realizados concomitantemente com seus horários vagos de pescaria, como foram pensados originalmente, pois eles não podem parar de trabalhar [...]" (p. 96), uma vez que esses dependem do trabalho para o sustento da família, sendo de prioridade o trabalho em vez dos estudos. O Projeto Garças se encontrava em execução, porém, "[...] segundo o presidente da Colônia Z-2, o trabalho não estava acontecendo como deveria" (p. 97); no Programa Nacional de Financiamento de Ampliação e Modernização da Frota Pesqueira, identificou-se que [...] pouco se observa no dia-a-dia dos pescadores, que os tenham beneficiado [...]" (p. 98), no Projeto Apoio à Cadeia Produtiva do Pescado Proveniente de Pesca Artesanal, sendo que pescadores disseram que mesmo tendo recebido verbas para a implantação de uma fábrica, não foi frutífera. No Programa Feira do Peixe constatou-se que não houve interesse da comunidade em executar o projeto (MENDES FILHO; CALLOU; SANTOS, 2010, p. 99).

Com isso, pode-se destacar que as dificuldades enfrentadas nas ações exógenas precisam estar alinhadas e muito bem estruturadas com o local e com a comunidade; "[...] definições sobre o que pesquisar, para quem pesquisar e o que fazer com os resultados são definições para serem feitas a priori da investigação" (PERRY; COELHO, 2010, p. 133), para que os resultados locais propostos sejam satisfatórios.

O fator exógeno, por si só, não consegue envolver a comunidade e impor-lhes o sentimento de pertença daquilo que se projeta por agentes externos, pois nem sempre o que se projeta por fora, ou seja, por autoridades ou por quaisquer pessoas sem vínculo direto com o local, é o que a comunidade espera e necessita.

Por isso, para que haja desenvolvimento local, é necessário desenvolver atividades endógenas bem articuladas com a comunidade. 


\section{COMUNIDADE, CULTURA E IDENTIDADE COMO MEIO PECULIAR DO DESENVOLVIMENTO LOCAL}

A temática de comunidade, cultura e identidade foi abordada na presente pesquisa por meio de relevantes bases de sustentação conceituais do Mestrado em desenvolvimento local para o ideal desenvolvimento local da comunidade.

Nesse sentido, de acordo com Bourlegat (2000), no artigo intitulado "Ordem local como força interna de desenvolvimento", as primeiras comunidades que se constituíram foram estabelecidas por pequenos grupos de pessoas que se fixaram e se organizaram de forma espontânea, restrita e isolada em um território, os quais, por meio da proximidade e intimidade conquistada pela convivência cotidiana, buscavam meios para obter melhores condições de convivência social.

No mesmo prisma temático, Ávila (2000), no relato "Pressupostos para Formação Educacional em Desenvolvimento Local", apontou que comunidade consiste em relacionamentos primários entre as pessoas, ou seja, aqueles relacionamentos que se estreitam por meio de vínculos que vão se formando entre as pessoas que vivem em um ambiente comum e interagem entre si em atividades cotidianas de forma espontânea e informal, mediados por relações interpessoais de vizinhos, amigos, parentes, filhos, entre outros, e que "[...] quanto mais próximos e inteirados são esses relacionamentos no âmbito de vida das pessoas tanto mais densos e comuns tendem a ser os sentimentos, interesses, objetivos e perfis de identidade histórico-social-cultural das pessoas neles envolvidas [...]" (ÁVILA, 2000, p. 71). No sentido de cooperação da comunidade para que o desenvolvimento local seja eficaz, Crevoisier (2003), no artigo "A abordagem dos meios inovadores: avanços e perspectivas", afirma que "[...] a cooperação não é permanente, mas ela proporciona a constituição de um capital relacional, permitindo que os atores locais se identifiquem e tenham acesso a diversas modalidades de recursos particulares" (CREVOISIER, 2003, p. 18), e que tais relações de cooperação superam os recursos monetários. Ponderou também Bourlegat (2000, p. 15) que “[...] com a expansão dos grupos, os conflitos por territórios aumentaram, vez que o interesse pelo domínio territorial se fez presente". Assim, com o êxito nas guerras, determinados grupos prevaleciam sobre outros e, com isso, a realidade interna e externa das pessoas e da comunidade passava por novas restruturações, destacando-se alterações sofridas no território, família, cultura, ordem local, classes sociais, hierarquias superiores, entre outras.

A comunidade então se reconhece como tal à medida que vai se legitimando como parte integrante de um espaço, constituída por locais e por características particulares de cultura e identidade, conforme asseguram Rímoli et al. (2000), no artigo "Biodiversidade, biotecnologia e conservação genética em desenvolvimento local". No entanto, por meio da diversidade cultural, observada principalmente pelas comunidades tradicionais, citam-se as comunidades indígenas e agricultores, que os conhecimentos tradicionais são de suma importância para análise da cultura de um povo, como também para conservação dos recursos genéticos e desenvolvimento econômico e social.

Grzeszczeszyn e Machado (2010) reforçam este pensamento no artigo "Políticas públicas para o desenvolvimento local: o caso de fomento às indústrias de móveis de Guarapuava, Paraná", ao afirmarem que: "[...] uma comunidade informada e inteligente, que compartilha conhecimento, constitui um fator favorável ao surgimento de vários processos como: a aprendizagem coletiva, a inovação, a transformação em uma região [...]" (GRZESZCZESZYN; MACHADO, 2010, p. 84). Na pesquisa de Kashimoto, Marinho e Russeff (2002), intitulada "Cultura, Identidade e 
Desenvolvimento Local: conceitos e perspectivas para regiões em desenvolvimento", acerca da cultura, identidade e desenvolvimento local, a observação relacionada ao desenvolvimento é somada com o olhar de um pesquisador; embora seja o agente local o ator de suma importância no cenário do desenvolvimento local, é a comunidade que precisa reconhecer, identificar e assumir o compromisso de desenvolvimento (KASHIMOTO; MARINHO; RUSSEFF, 2002, p. 39). A cultura das pessoas que ocupam um espaço pode ser originada das próprias características de cada pessoa que ali vive e, ao interagirem entre si, essas pessoas adaptam-se umas às outras e ao meio, desenvolvendo, dessa forma, um estilo de viver e compreender o local de maneira especial e única.

Cultura se desenvolve por meio de posturas singulares que são submetidas em uma comunidade, difundidas entre todos e que passam a fazer parte inconscientemente ou conscientemente dos ritos de vida do povo.

Nesse sentido, Kashimoto, Marinho e Russeff (2002) citaram a abrangência da cultura, exemplificando com os "[...] conhecimentos técnicos, costumes relativos a roupas e alimentos, religião, mentalidade, valores, língua, símbolos, comportamento sócio-político e econômico, formas autóctones de tomar decisões e de exercer o poder [...]" (KASHIMOTO; MARINHO; RUSSEFF, 2002, p. 35), e conceituaram cultura popular local como relações intensas entre a comunidade e o local em que vivem (p. 36).

Contudo o desenvolvimento local precisa estar, de forma clara e objetiva, adequado às pessoas e ao local, em todos os seus aspectos culturais, tradições, inspirações e anseios. Assim, Kashimoto, Marinho e Russeff (2002) afirmam ainda que, com relação à cultura, verifica-se a necessidade de que o desenvolvimento local aconteça, desde que a cultura de uma comunidade, suas características étnicas e histórias sejam respeitadas.

Na perspectiva de Castilho, Arenhardt e Bourlegat (2009), no artigo "Cultura e identidade: os desafios para o desenvolvimento local no assentamento Aroeira, Chapadão do Sul, MS", a cultura é observada quando "[...] cada povo ou grupo social tem as suas mais diversas formas de criatividade e dinamismo", sendo ela a responsável por "dar credibilidade de existência e identidade a um grupo de pessoas ou comunidade" (CASTILHO ARENHARDT; BOURLEGAT, 2009, p. 161). Quando se menciona a cultura de um povo, pode-se identificar involuntariamente a identidade do grupo, sendo que, conforme Castilho, Arenhardt e Bourlegat (2009, p. 162), pode-se constatar uma "[...] construção de significados culturais, sociais e econômicos que são internalizados pelos próprios membros que fazem parte do grupo ou sociedade e por meio deles vão construindo a sua identidade". A identidade de cada sociedade, a organização customizada de acordo com os anseios de cada grupo, assim conhecendo e reconhecendo a identidade, especificidades de um povo, consegue pensar em ações que se identificam com esses grupos e estreitam os conhecimentos sobre: comunidade, cultura e identidade do local, para que as ferramentas de desenvolvimento sejam satisfatoriamente aplicadas (CASTILHO; ARENHARDT; BOURLEGAT, 2009).

Evidencia-se a necessidade de valorizar aquilo que foi aos poucos concretizado e adaptar as necessidades humanas à realidade sem permitir o desaparecer do sentido da identidade local, sendo esta uma forma do desenvolvimento da comunidade, agregando valor e concretizando a identidade. 


\section{COSTUMES E TRADIÇÕES: CARACTERÍSTICAS INDISPENSÁVEIS PARA A FORMAÇÃO DA IDENTIDADE LOCAL}

No presente tópico, evidenciam-se os aspectos relevantes acerca dos costumes e das tradições no desenvolvimento local, sendo que o progresso de um local precisa estar alinhado às tradições e aos costumes de cada povo, pois é de suma importância o apreço e a perpetuação dos valores construídos por um povoado no decorrer de muitos anos para que a identidade do território se estabeleça.

Com relação à tradição, os autores Valentini et al. (2009, p. 195-206) publicaram o artigo intitulado "Uso e conservação da negramina (Siparuna guianensis Aubl.) em Bom Sucesso, Várzea Grande-MT" e frisaram que o estudo teve como finalidade investigar a transmissão do saber local, dos habitantes mais velhos para os mais novos, na Comunidade Ribeirinha. Nesse sentido, verificaram que uma das tradições locais da região era a utilização das folhas conhecidas por negramina, usada no banho, quando da necessidade de cura de gripe, febre e demais enfermidades. Dos resultados apresentados, analisou-se que a tradição da utilização da planta pelas gerações mais novas se perdeu, muitos descendentes da comunidade tradicional local nem sequer conhecem a planta. Nesse sentido, nota-se como a tradição pode se perder com o passar dos anos, se não for preservada (VALENTINI et al., 2009, p. 204). Pode-se dizer, então, que o povoado é reconhecido pelos seus costumes e pelo seu habitar, portanto, manter os princípios presentes, melhorando as necessidades particulares de cada grupo, permite que a tradição de gerações permaneça viva com o passar dos anos.

No mesmo norte, Rego, Brand e Costa (2010), no artigo “Recursos Genéticos, biodiversidade, conhecimento tradicional Kaiowá e Guarani e o desenvolvimento local", trouxeram para a pesquisa a necessidade de atenção aos conhecimentos tradicionais de uma etnia indígena, para que as tradições fossem mantidas e adaptadas à realidade atual. Para tanto, a cautela com relação ao desenvolvimento de uma comunidade é de suma importância, pois a preservação da tradição precisa ter continuidade pelos costumes enraizados na vida e no cotidiano das pessoas e do local e, por ter importância singular, deve ser transferida de geração para geração. Os mesmos autores citam a tradição de comunidades indígenas com relação à natureza e ao sobrenatural (REGO; BRAND; COSTA, 2010, p. 64).

Contudo a tradição é um dos elementos-chave para que se tenha um desenvolvimento local saudável da comunidade e, com intervenções e fragmentações, pode-se resultar no enfraquecimento do local.

Costa et al. (2010, p. 164), no artigo "Democracia e desenvolvimento local em assentamentos rurais", apontam a importância da cooperação como fator imprescindível para que uma comunidade consiga atingir seus objetivos de desenvolvimento e correlacionam, também, a importância das cooperações espontâneas, que estão fortemente ligadas às identidades sedimentadas pelo sentimento de pertença no local, que advém da tradição, e são estruturadas por fortes grupos sociais ou comunidades.

Na pesquisa de Pasa e Ávila (2010), nominada "Ribeirinhos e recursos vegetais: a etnobotânica em Rondonópolis, Mato Grosso, Brasil", são evidenciados pontos relevantes acerca dos saberes locais e tradições, ao se analisar o cultivo das plantas pelas famílias da região em sistemas de quintais, hortas, fundos das casas e roças. Portanto, com a chegada de novos moradores na região, a cultura local pode sofrer influências pela grande variedade de plantas 
que os novos moradores partilham nos locais, os saberes locais tornam-se múltiplos e podem influenciar a cultura e as tradições na comunidade. No cenário destacado, verifica-se que a principal forma de transmissão do conhecimento é oral e realizada de forma simples, no dia a dia, conforme a situação que estão vivendo, não se observando tradições e costumes escritos em documentos ou em livros (PASA; ÁVILA, 2010, p. 195-202).

Apresenta-se, dessa forma, a importância de se conservar também as culturas e tradições para um melhor aproveitamento e preservação dos recursos naturais, bem como o fato de que as pessoas que se importam com os modos tradicionais de se viver não perdem sua essência, no caso em análise, o respeito pela natureza está acima de quaisquer interesses da cultura capitalista que permeia o mundo.

\section{CONSIDERAÇÕES FINAIS}

A pesquisa evidenciou que a revista Interações é base de sustentação do Programa de Pós-Graduação stricto sensu em Desenvolvimento Local da Universidade Católica Dom Bosco, como também base norteadora para outros pesquisadores, docentes, discentes, agentes locais e demais interessados nos fundamentos da temática estudada.

Observou-se que, dos anos 2000 a 2010, muitos conceitos de desenvolvimento local foram estudados e discorridos pelos autores que publicaram na revista, sendo que ficou evidenciada, nas considerações acerca do desenvolvimento local, a importância das abordagens conceituais para bem compreender as observações indispensáveis dos pesquisadores da área, para o adequado desenvolvimento de um local. Além do mais, nos artigos discorridos, foram identificadas, nas pesquisas realizadas, forças que impulsionam e restringem o progresso local quando da abordagem remetida ao desenvolvimento local endógeno e fatores exógenos.

Com isso, a publicidade das evidências trazidas permite orientar acertos, acompanhar e corrigir caminhos cometidos por erros praticados por comunidades, agentes locais e agentes externos no percurso das pretensões traçadas.

Registrou-se a importância do capital humano, capital social, comunidade, cultura, identidade, costumes e tradições para que o desenvolvimento local siga trajetórias voltadas para o atendimento primordial das necessidades primárias do indivíduo, para que, consequentemente, as demais carências sejam supridas. No mesmo sentido, levantaram-se conceitos e características de comunidade para bem entendê-la; cultura para ressaltar como ocorre o seu processo de formação; identidade com o objetivo de perceber a complexidade que impera na sua constituição até a consolidação do meio; costumes e tradições a fim de salientar a magnitude de preservar a identidade do lugar.

\section{REFERÊNCIAS}

ÁVILA, V. F. Realimentando discussão sobre teoria de Desenvolvimento Local (DL). Interações, Campo Grande, v. 8, n. 13, p. 133-40, set. 2006. Disponível em: https://www.interacoes.ucdb.br/interacoes/ issue/archive. Acesso em: 26 abr. 2020.

ÁVILA, V. F. Pressupostos para Formação educacional em desenvolvimento local. Interações, Campo Grande, v. 1, n. 1, p. 63-76, set. 2000. Disponível em: https://www.interacoes.ucdb.br/interacoes/issue/ archive. Acesso em: 26 abr. 2020.

BENKO, Georges. A recomposição dos espaços. Interações, Campo Grande, v. 1, n. 1, p. 7-12, mar. 2001. 
Disponível em: https://www.interacoes.ucdb.br/interacoes/issue/archive. Acesso em: 26 abr. 2020.

BOURLEGAT, C. A. Ordem local como força interna de desenvolvimento. Interações, Campo Grande, v. 1, n. 1, p. 13-20, set. 2000. Disponível em: https://www.interacoes.ucdb.br/interacoes/issue/archive. Acesso em: 26 abr. 2020.

CASTILHO, M. A. de.; DERMIRDJIAN.; Walter. A Rádio UCDB e o Desenvolvimento Local. Interações, Campo Grande, v. 6, n. 9, p. 59-63, set. 2004. Disponível em: https://www.interacoes.ucdb.br/interacoes/issue/ archive. Acesso em: 26 abr. 2020.

CASTILHO, M. A.; ARENHARDT, M. M.; BOURLEGAT, C. A. Cultura e identidade: os desafios para o desenvolvimento local no assentamento Aroeira, Chapadão do Sul, MS. Interações, Campo Grande, v. 10, n. 2, p. 159-69, jul./dez. 2009. Disponível em: https://www.interacoes.ucdb.br/interacoes/issue/archive. Acesso em: 26 abr. 2020.

COELHO, I. S.; ÁVILA, V. F. de. Performances comunitárias e vieses teóricos sobre potencialidades de participação no Jardim Sayonara - Campo Grande-MS - em ótica de Desenvolvimento Local. Interações, Campo Grande, v. 10, n. 1, p. 97-117, jan./jun. 2009. Disponível em: https://www.interacoes.ucdb.br/ interacoes/issue/archive. Acesso em: 26 abr. 2020.

COSTA, L. F.; ÍTAVO, L. C. V.; SOARES, C. M.; CEREDA, M. P.; MACIEL, J. C.; ÍTAVO, C. C. B. F. Democracia e desenvolvimento local em assentamentos rurais. Interações, Campo Grande, v. 11, n. 2, p. 161-9, jul./dez. 2010. Disponível em: https://www.interacoes.ucdb.br/interacoes/issue/archive. Acesso em: 26 abr. 2020.

CREVOISIER, O. A abordagem dos meios inovadores: avanços e perspectivas. Interações, Campo Grande, v. 4, n. 7, p. 15-25, set. 2003. Disponível em: https://www.interacoes.ucdb.br/interacoes/issue/archive. Acesso em: 26 abr. 2020.

GRZESZCZESZYN, G.; MACHADO, H. P. V. Políticas públicas para o desenvolvimento local: o caso de fomento às indústrias de móveis de Guarapuava, Paraná. Interações, Campo Grande, v. 11, n. 1, p. 81-92, jan./jun. 2010. Disponível em: https://www.interacoes.ucdb.br/interacoes/issue/archive. Acesso em: 26 abr. 2020.

IORIO, S. M.; ARCE, D. M.; MAGALHÃES, J.; MATTOS, A. B.; ZANON, A. M. A perspectiva da educação ambiental e o processo histórico do saneamento básico: a instalação das redes de água e esgoto nos municípios de Campo Grande/MS e Dourados/MS. Interações, Campo Grande, v. 10, n. 1, p. 63-72, jan./jun. 2009. Disponível em: https://www.interacoes.ucdb.br/interacoes/issue/archive. Acesso em: 26 abr. 2020.

KASHIMOTO, E. M.; MARINHO, M.; RUSSEFF, I. Cultura, identidade e desenvolvimento local: conceitos e perspectivas para regiões em desenvolvimento. Interações, Campo Grande, v. 3, n. 4, p. 35-42, mar. 2002. Disponível em: https://www.interacoes.ucdb.br/interacoes/issue/archive. Acesso em: 26 abr. 2020.

MACIEL, J. C. Exame de ressonância sobre "paciência" e desenvolvimento local endógeno em subsolo teológico. Interações, Campo Grande, v. 9, n. 1, p. 99-108, mar. 2008. Disponível em: https://www. interacoes.ucdb.br/interacoes/issue/archive. Acesso em: 26 abr. 2020.

MENDES FILHO, O. R.; CALLOU, A. B. F.; SANTOS, M. S. T. Políticas públicas e extensão pesqueira em Cabedelo, Paraíba. Interações, Campo Grande, v. 11, n. 1, p. 93-100, jan./jun. 2010. Disponível em: https:// www.interacoes.ucdb.br/interacoes/issue/archive. Acesso em: 26 abr. 2020.

PASA, M. C.; ÁVILA, G. de. Ribeirinhos e recursos vegetais: a etnobotânica em Rondonópolis, Mato Grosso, Brasil. Interações, Campo Grande, v. 11, n. 2, p. 195-204, jul./dez. 2010. Disponível em: https://www. interacoes.ucdb.br/interacoes/issue/archive. Acesso em: 26 abr. 2020. 
PERRY, L. S. P.; COELHO, F. M. G. Argumentações acerca de questões técnico-científicas: disputas, valores e ideais de mundo. Interações, Campo Grande, v. 11, n. 2, p. 127-135, jul./dez. 2010. Disponível em: https://www.interacoes.ucdb.br/interacoes/issue/archive. Acesso em: 26 abr. 2020.

PIRES, E. S. L. As lógicas territoriais do desenvolvimento: diversidades e regulação. Interações, Campo Grande, v. 8, n. 2, p. 155-63, set. 2007.

REGO, F. L. H.; BRAND, A. J.; COSTA, R. B. Recursos genéticos, biodiversidade, conhecimento tradicional Kaiowá e Guarani e o desenvolvimento local. Interações, Campo Grande, v. 11, n. 1, p. 55-69, jan./jun. 2010. Disponível em: https://www.interacoes.ucdb.br/interacoes/issue/archive. Acesso em: 26 abr. 2020.

RÍMOLI, A. O.; ARRUDA, E.; RÍMOLI, J.; BUENO, N.; COSTA, R.. Biodiversidade, Biotecnologia e Conservação Genética em Desenvolvimento Local. Interações, Campo Grande, v. 1, n. 1, p. 21-30, set. 2000. Disponível em: https://www.interacoes.ucdb.br/interacoes/issue/archive. Acesso em: 26 abr. 2020.

SARAIVA, M. S.; CALLOU, A. B. F. Políticas públicas e estratégias de comunicação para o desenvolvimento local de comunidades pesqueiras de Pernambuco. Interações, Campo Grande, v. 10, n. 1, p. 73-81, jan./jun. 2009. Disponível em: https://www.interacoes.ucdb.br/interacoes/issue/archive. Acesso em: 26 abr. 2020.

SILVA, C. L.; LOPES, C..; MICHON JUNIOR, W. Intervenção do Estado e desenvolvimento local: uma análise cross section dos municípios paranaenses. Interações, Campo Grande, v. 10, n. 1, p. 41-53, jan./jun. 2009. Disponível em: https://www.interacoes.ucdb.br/interacoes/issue/archive. Acesso em: 26 abr. 2020.

VALENTINI, C. M. A.; COELHO, M. F. B.; ORTíZ, C. E. R.; ALMEIDA, J. D. Uso e conservação da negramina (Siparuna guianensis Aubl.) em Bom Sucesso, Várzea Grande-MT. Interações, Campo Grande, v. 10, n. 2, p. 195-206, jul./dez. 2009. Disponível em: https://www.interacoes.ucdb.br/interacoes/issue/archive. Acesso em: 26 abr. 2020.

\section{Sobre os autores:}

Karen Giuliano: Mestrado em Desenvolvimento Local em Contexto de Territorialidades pela Universidade Católica Dom Bosco (UCDB). Pós-Graduação Lato Sensu em Direito Civil e Processual Civil; e em Direito do Trabalho e Processo do Trabalho pela UCDB. Bacharelado em Ciências Jurídicas e em Administração de Empresas; graduação tecnológica em Gestão de Recursos Humanos; Graduação em Negócios Imobiliários; em Processos Gerenciais; em Logística; e em Gestão Comercial pela UCDB. E-mail: karengiuliano@gmail.com, Orcid: https://orcid.org/0000-0002-9372-2453

Luciane Almeida: Doutorado e Mestrado em Serviço Social pela Universidade Estadual Paulista Júlio de Mesquita Filho (Unesp). Graduação em Serviço Social e Pedagogia pela Unesp. Professora do Mestrado/Doutorado em Psicologia da Universidade Católica Dom Bosco (UCDB). E-mail: Ipinhoa@hotmail.com, Orcid: https://orcid.org/0000-0002-7003-9264

Maria Augusta Castilho: Pós-doutorado em Linguística pela Universidade de São Paulo (USP). Doutorado em Ciências Sociais - História do Brasil pela USP. Professora no Programa de Pós-Graduação em Desenvolvimento Local e no Curso de Graduação em História da Universidade Católica Dom Bosco (UCDB). E-mail: m.a.castilho@terra.com.br, Orcid: https://orcid.org/0000-0001-5235-3164 
